\section{A Endocrinologia Pediátrica ea Sociedade Brasileira de Endocrinologia e Metabologia}

$E^{\prime}$ M MEIO SÉCULO DE EXISTÊnCIA A SBEM tornou-se uma das maiores Sociedades de Endocrinologia, suplantando a maioria das congêneres em todos os continentes. Seu crescimento deveu-se a vários fatores, entre os quais sobressaem o trabalho das várias $D$ iretorias $\mathrm{N}$ acionais e R egionais que dirigiram a sociedade ao longo dos cinqüenta anos de sua existência, a participação ativa da quase totalidade dos sócios nos conclaves nacionais e regionais de endocrinologia organizados sob sua égide, e a existência de um órgão de divulgação científica, os ABE \& M , cuja qualidade científica e editorial aumentou consideravelmente nos anos recentes.

J unto com a expansão da SBEM , algumas sub-especialidades cresceram, adquiriram contornos mais nítidos e começaram a aglutinar um número cada vez maior de endocrinologistas e outros profissionais com maior interesse em ampliar seus conhecimentos e aprofundar suas pesquisas naquelas sub-especialidades. $O$ sucesso e a qualidade dos Encontros de Tireóide e dos Simpósios Internacionais de N euroendocrinologia fizeram com que as últimas D iretorias $\mathrm{N}$ acionais da SBE M, entendendo 0 novo processo de crescimento da endocrinologia brasileira, criassem os D epartamentos de sub-especialidades a fim de evitar sua fragmentação e, por conseqüência, o aparecimento de pequenas sociedades, quase como um contra-senso à essência da endocrinologia, que é seu caráter abrangente e integrador.

A criação dos D epartamentos de Tireóide e de N euroendocrinologia foi um processo de formalização do que já existia. O s demais D epartamentos, de Endocrinologia Básica, de Adrenal, de Endocrinologia Pediátrica e de Endocrinologia Feminina serviram não só para manter a integridade da SBEM como, ao mesmo tempo, criar novos nichos de interação de vários grupos de pesquisa ou de endocrinologistas que procuram expandir seus conhecimentos e melhorar a qualidade de sua prática clínica. A criação, recentemente, da Federação Brasileira de Sociedades de Endocrinologia e M etabologia (FEBRASEM), tendo como denominador comum os ABE\& M , mostra a força da SBEM e seu caráter de "ancestralidade" sobre as sociedades de sub-especialidades saídas de seu seio.

$\mathrm{N}$ as últimas décadas a endocrinologia pediátrica tem sido uma área altamente atraente para clínicos e cientistas (não obrigatoriamente médicos) de outras especialidades. E mbora fortemente ligada à pediatria, ela apresenta uma extensa interface com outras disciplinas, o que tem propiciado sua expansão e sub-especialização. A SBEM , a Associação M édica Brasileira, 0 Conselho Federal de M edicina e a Sociedade Brasileira de Pediatria, a partir deste ano, passarão a reconhecer o título de Área de Atuação em Endocrinologia Pediátrica, mediante prova de proficiência e outros pré-requisitos da formação profissional. Isto vem materializar a aspiração de um grupo substancial e crescente de endocrinologistas clínicos que têm se dedicado exclusiva ou preferencialmente à endocrinologia pediátrica.

É inegável a expansão da endocrinologia pediátrica em nosso país e a existência de grupos de pesquisadores e clínicos voltados à sua prática,

\section{Luiz de Lacerda Filho' Margaret C .S. Boguszewski ${ }^{2}$}

${ }^{1} \mathrm{C}$ hefe do D epartamento de Pediatria e da U nidade de Endocrinologia Pediátrica da U niversidade Federal do Paraná (U FPR ) e Ex-Presidente do $D$ epartamento de Endocrinologia Pediátrica da SBEM

${ }^{2}$ Professora A djunta do D epartamento de Pediatria da UFPR e

D outora em Endocrinologia Pediátrica pela U niversidade de Gotemburgo, Suécia. 
ensino e pesquisa. Além do mais, a oferta de programas de pós-graduação em endocrinologia pediátrica, especialmente a nível acadêmico, vem aumentando nos últimos anos. Aos serviços pioneiros implantados na U niversidade Federal do Paraná pelo Professor Romolo Sandrini, e no Instituto da C riança na U niversidade de São Paulo, pela Professora N uvarte Setian, na década de setenta, juntaram-se outros como os da Santa C asa de São Paulo, da U NICAMP, da U NIFESP, da UFRJ, da UFM G, da UFSC, entre outros.

0 presente número dos $A B E \& M$ reúne uma coletânea de temas de endocrinologia pediátrica. Para sua confecção foram convidados vários grupos envolvidos em pesquisa clínica ou básica, as quais interessam o endocrinologista de um modo geral e o endocrinologista pediátrico em particular. 0 que caracteriza cada grupo de autores é o conjunto de sua produção científica de excelente qualidade, publicada nos $A B E \& M$ ou em revistas internacionais, e que atesta 0 crescimento da SBEM no contexto da endocrinologia mundial.

0 sucesso do presente número dos $A B E \& M$ propiciará a outros grupos de endocrinologistas traba-
Ihando ativamente na área (clínica ou básica) de endocrinologia pediátrica a usar com mais freqüência OS ABE \& M para veicular suas experiências e mostrar 0 status quo da endocrinologia pediátrica no Brasil.

$O$ empenho do Editor-C hefe dos ABE\& M, D r. Cláudio Kater, cuja política editorial tem prestigiado os vários D epartamentos da SBEM , e a aquiescência dos colegas que na prática, no ensino e na pesquisa têm se destacado por sua produção na área de endocrinologia pediátrica e participam desta publicação, foram fundamentais para que pudéssemos brindar os colegas endocrinologistas e de outras especialidades com os artigos aqui inseridos.

O D epartamento de Endocrinologia Pediátrica da SBEM é ainda muito novo. A dedicação do $\mathrm{Dr}$. Walter Bloise, seu primeiro presidente, auxiliado por seus colegas Berenice M endonça, I vo Arnhold e Ana Cláudia $L$ atrônico, foi crucial para que após sua criação se tornasse irreversível. Com esta publicação, e agora sob a presidência do Dr. Carlos Alberto Longui, deverá continuar atuante e produtivo. Assim vamos contribuindo pelo engrandecimento da SBEM e fazendo a história da endocrinologia no Brasil. 